\title{
Effects of active molecules of Korean pine seed on rodent health and implications for forest regeneration
}

\author{
Gang $\mathrm{Wei}^{1} \cdot \mathrm{Ke} \mathrm{Rong}^{2} \cdot \mathrm{Kexin} \mathrm{Yang}^{1} \cdot \mathrm{Zhiying} \mathrm{Bao}^{1}$. \\ Xiaotong Zhang ${ }^{1} \cdot$ Zhi Zhang $^{1} \cdot$ Yanni Gong ${ }^{3}$. \\ Jiafu Wang ${ }^{4}$
}

Received: 6 April 2021 / Accepted: 21 June 2021 / Published online: 6 August 2021

(C) The Author(s) 2021

\begin{abstract}
After maturation, Korean pine (Pinus koraiensis Siebold \& Zucc.) seeds often cannot disperse to reach a suitable germination site. It is therefore difficult to naturally regenerate by itself and relies on animal dispersal. Squirrels hoard pine seeds as winter food and Korean pine seeds stored for overwintering might become the source of regeneration of the species. From field observations, the pine seeds are the food preference for squirrels during autumn in the Lesser Khingan Mountains in Northeast China. Such preference by squirrels has been attributed to high seed energy content and the ease of seed storage. However, it may also be expected from nutritional aspects that a coevolutionary relationship between squirrels and Korean pine species could be partially explained by the effect of active seed components and their
\end{abstract}

Project funding: This work was supported by the Heilongjiang Province Hundred Million Engineering Science and Technology Major Project (2020ZX07B01).

The online version is available at http://www.springerlink.com.

Corresponding editor: Yu Lei

Zhi Zhang

ldzhangzhi@126.com

Yanni Gong

369909311@qq.com

1 School of Forestry, Northeast Forestry University, Harbin 150040, People's Republic of China

2 College of Wildlife and Protected Area, Northeast Forestry University, Harbin 150040, People's Republic of China

3 Beidahuang Wondersun Dairy Co. Ltd, Harbin 150040, People's Republic of China

4 Inner Mongolia Greater, Khingan Range Forestry Science and Technology Research Institute, Yakeshi 022150, People's Republic of China physiological regulatory effects on squirrels. To test this hypothesis, control experiments were carried out to examine the modulatory effects of Korean pine nut oil (PNO) on intestinal microbiota, inflammatory profile and oxidative stress in mice. The results showed that, compared with mice fed a high-fat diet, PNO significantly improved the physical and the healthy state of mice. Histological analysis of the liver and epididymal fat tissue showed that PNO alleviated liver and adipocyte lesions, and inflammation caused by high-fat diets. PNO also significantly decreased atherosclerotic index and ameliorate serum lipid accumulation to prevent cardiovascular disease, which effect the positive control SG group. Moreover, PNO elevated superoxide dismutase and glutathione peroxidase enzyme activities and reduced malondialdehyde levels in the serum. 16S rRNA sequencing showed that PNO restored intestinal microbiota composition, significantly increasing the relative abundance of Lactobacillus and Akkermansia bacteria. These results suggest that Korean pine seeds not only provide adequate fat, protein and energy for squirrels, but also promote physical health and improve body immunity.

Keywords Plant-animal interactions $\cdot$ Natural regeneration $\cdot$ Coevolution $\cdot$ Rodent $\cdot$ Korean pine seed dispersal

$\begin{array}{ll}\text { Abbreviations } \\ \text { PNO } & \text { Pinus koraiensis } \text { Nut oil } \\ \text { TC } & \text { Total cholesterol } \\ \text { TG } & \text { Triglyceride } \\ \text { LDL-C } & \text { Low-density lipoprotein cholesterol } \\ \text { HDL-C } & \text { High-density lipoprotein cholesterol } \\ \text { HFD } & \text { High-fat diet } \\ \text { PLA } & \text { Pinolenic acid } \\ \text { LA } & \text { Linoleic acid }\end{array}$




$\begin{array}{ll}\text { ND } & \text { Normal diet } \\ \text { SG } & \text { Simvastatin } \\ \text { MDA } & \text { Malondialdehyde } \\ \text { SOD } & \text { Superoxide dismutase } \\ \text { GSH-Px } & \text { Glutathione peroxidase } \\ \text { IL-6 } & \text { Interleukin-6 } \\ \text { TNF- } \alpha & \text { Tumor necrosis factor-alpha } \\ \text { AI } & \text { Atherosclerotic index } \\ \text { H\&E } & \text { Hematoxylin and eosin } \\ \text { OUT } & \text { Operational taxonomic unit } \\ \text { F/B } & \text { Firmicutes/ Bacteroidetes } \\ \text { CCK } & \text { Cholecystokinin } \\ \text { GLP-1 } & \text { Glucagon-like peptide-1 } \\ \text { NO } & \text { Nitric oxide }\end{array}$

\section{Introduction}

Research on the coevolution or cooperative evolution of animals and plants has become an important topic in conservation biology and recovery ecology (Wall and Jenkins 2011; Gómez et al. 2018; Silva et al. 2021). Many plant species are dispersed by animals (e.g., birds, rodents and ants) that feed on the fruits or seeds while foraging, providing an unexpected dispersal service and forming a coevolutionary relationship. Korean pine is one of the most valuable evergreen species in northeast China (Kaviriri et al. 2020) and its seed is a quality food source that provides high energy and is rich in phospholipids, unsaturated fatty acids, vitamins and minerals (Nergiz and Doenmez 2004; No et al. 2015). Scatter-hoarding rodents, such as squirrels (Sciurus vulgaris L.), have the habit of feeding and storing pine seeds. However, whether there is a coevolutionary relationship between squirrels and Korean pine, and if squirrels are attracted to forage and disperse seeds is a question worthy of study. Korean pine seeds are relatively large and wingless and not easily dispersed to suitable germination sites, which indicates that natural regeneration is almost totally dependent on animals.

Scatter-hoarding rodents obtain energy by consuming pine seeds immediately or disperse seeds in caches a certain distance from the parent tree (Wall 1990; Roth and Wall 2005). If forgotten, these seeds may germinate into seedlings to self-renewal of the species when environmental conditions are favourable (Wall and Joyner 1998; Wall 2001). In general, scatter-hoarding rodents are not only pine seed predators but also act as seed disseminators, facilitating the establishment of pine seedlings (Hollander and Wall 2004; Steele et al. 2005). The mutualism of scatter-hoarding rodents and Korean pine is a good subject for the study of cooperative evolution of animals and plants, an important issue for forest ecologists globally.
Seed quality is affected by a variety of factors, including their size, perishability, nutrients and secondary compounds, affecting scatter-hoarding rodent behavior (Lichti et al. 2017; Vander et al. 2019). There are several reasons that squirrels may prefer pine seeds: (i) seeds provide sufficient energy for scatter- hoarding rodents; and, (ii) seeds with hard shells are suitable for storage (Molinari et al. 2006; Zhang et al. 2014; Sundaram et al. 2018). A number of studies have focused on the relationship between seed traits and fate, and a few studies have examined the internal mechanism of active components on the behavior decisions of scatter-hoarding rodents. It is hypothesized that the coevolutionary relationship between squirrels and Korean pine could be explained by the influence of active seed components and high nutrient values. To address this hypothesis, mice were fed pine seed oil in vivo experiments in order to investigate why squirrels eat pine nuts.

Pine nut oil (PNO) is an edible vegetable oil extracted from Korean pine nuts. The main polyunsaturated fatty acids (PUFAs) include linoleic acid (45.2\%), oleic acid (27.5\%) and pinolenic acid (PLA) (14.6\%). PLA is a characteristic component of PNO, and not found in other vegetable oils (Destaillats et al. 2010). Previous studies have shown that PNO has potential pharmacological properties, including decreasing appetite, body weight, lipid-lowering, and antioxidation, anticancer and anti-inflammatory effects (Xie et al. 2016). In addition the lipid-lowering effects of PNO have been verified in animals (Le et al. 2012; Chung et al. 2017). Asset et al. (1999a, b) found that, compared to the intake of other lipids, (such as sunflower seed oil, coconut oil or lard), PNO intake lowers the cholesterol level in mice (Asset et al. 2001). Soyoung et al. (2016) noted that the intake of PNO could alleviate triacylglycerol accumulation in mice fed a high-fat diet.

By field observation of the food composition of squirrels, pine seeds are the main food. We speculated that the active components of pine seeds on antioxidant, anti-inflammatory and blood lipid levels may be why squirrels prefer pine nuts. To better understand the coevolutionary relationship between squirrels and Korean pine, a high-fat diet mice model was used for physiological activity tests to investigate the influence of seed oil active components. Insufficient number of squirrels were available for medical experiments so Kunming mice were used as the experimental model. It is common in small experiments and easily managed. A series of physiological and biochemical tests, such as blood lipids, inflammation, oxidative stress and gut microbiota in mice were carried out to determine possible internal mechanisms of pine seeds on the foraging preference of squirrels. The results should provide a fresh perspective for the study of the cooperative evolution of scatter-hoarding rodents and Korean pine. 


\section{Materials and methods}

\section{Study area}

The research was carried out from April to October 2014 in Liangshui National Nature Reserve in the Lesser Khingan Mountains of Heilongjiang Province, northeastern China $\left(128^{\circ} 47^{\prime} 8^{\prime \prime}-128^{\circ} 57^{\prime} 19^{\prime \prime}\right.$ E, $\left.47^{\circ} 6^{\prime} 49^{\prime \prime}-47^{\circ} 16^{\prime} 10^{\prime \prime} \mathrm{N}\right)$. This area has a typical temperate continental monsoon climate. Winters are long and very cold. The climate is changeable in spring and autumn. The Reserve is one of the typical distribution areas of Korean pine and broad-leaved mixed forest in China. The core area of the Reserve is 3740 ha, including 2375 ha of natural Korean pine. The main tree species are Korean pine (Pinus koraiensis Siebold \& Zucc.), red spruce (Picea koraiensis), scale spruce (Picea jezoensis (Siebold \& Zucc.) Carr.), fir (Abies jezoensis Siebold \& Zucc.), Xing'an larch (Larix gemlini), Manchurian walnut (Juglans mandshurica), amur cork-tree (Phellodendron amurense), Manchurian ash (Fraxinus mandshurica), elm (Ulmus propingua), Japanese white birch (Betula platyphylla Sukaczev). The main undergrowth shrubs are honeysuckle (Lonicera japonica Thunb.), hazelnut (Corylus heterophylla Fisch.), pearl plum (Sorbaria sorbifolia (L.) A. Br) and Amur lilac (Spiraea salicifolia L.), and acanthopanax root (Acanthopanax senticosus (Rupr. Maxim.) Harms).

\section{Observation on field feeding behavior}

The field survey of squirrel food composition in different seasons was conducted in the spring, summer and autumn of 2014. According to the climate characteristics of the reserve, April to May is spring, June to July summer, and September to October autumn. Daily observations were at 8:00-11:00 a.m. and 13:00-16:00 p.m. as squirrels are more active during these times. The method of continuous recording of target animals was used to record the feeding process during peak periods of squirrel activity. Five fixed observation points were selected in the area where the squirrels often moved, with intervals of $50 \mathrm{~m}$. One squirrel was randomly selected as the observation object at each observation point, aided by Bushnell binoculars $(10 \times 50)$, from a maximum distance of $30 \mathrm{~m}$. The species that the squirrel fed on and the number of times in one day were recorded. Feeding times of five squirrels for each plant species were noted and an average determined. A chi-square test was used to see whether there was a significant difference in the feeding frequency of each food source.

\section{Food storage in the autumn}

Squirrels are scatter-hoarding rodents. In the autumn of 2013, food storage behavior in the field was recorded and six storage holes were identified (Fig. 1). Korean pine nuts in these storage holes were divided into shelled and unshelled pine nuts and numbers recorded. One-way ANOVA was used to test whether there were differences in the quantity and weight of these two forms of pine nuts.

\section{Preparation and chemical composition analysis of PNO}

Pine nut powder $(100 \mathrm{~g})$ was added to a beaker with hexane $(1: 1, \mathrm{~V} / \mathrm{V})$ and stirred thoroughly and the procedure repeated three times. $\mathrm{N}$-hexane was removed at $35^{\circ} \mathrm{C}$ by a rotary evaporator. The prepared $\mathrm{PNO}$ was stored at $4{ }^{\circ} \mathrm{C}$ until further use (Hou et al. 2018). The composition of the PNO sample was measured by gas chromatography-mass spectrometry (GC-MS) according to Chen et al. (2016) with slight modifications. GC-MS analysis was carried out by a Trace1310ISQ (Thermo Fisher Scientific Inc., Waltham, MA, USA) system with a TG-5 MS capillary column (30 $\mathrm{m} \times 0.25 \mathrm{~mm} \times 0.25 \mu \mathrm{m}$, Thermo Fisher Scientific). PNO was determined by GC-MS by the methylated reaction (Nergiz and Doenmez 2004). Helium was used as the carrier gas at a flow rate of $1.2 \mathrm{~mL} \mathrm{~min}^{-1}$. Injection port temperatures were set at $290{ }^{\circ} \mathrm{C}$. The starting column temperature was $80^{\circ} \mathrm{C}$ for $1 \mathrm{~min}$, raised to $200^{\circ} \mathrm{C}$ at $10^{\circ} \mathrm{C} \mathrm{min}^{-1}$ and then to $250{ }^{\circ} \mathrm{C}$ at $5{ }^{\circ} \mathrm{C} \mathrm{min}^{-1}$. The final temperature was to $270{ }^{\circ} \mathrm{C}$ at a rate of $2{ }^{\circ} \mathrm{C} \mathrm{min}^{-1}$ for $3 \mathrm{~min}$. The volume injected was $1 \mathrm{~mL}$. Mass spectra were obtained by electron ionization at $70 \mathrm{eV}$ and scanned from 30 to $400 \mathrm{~m} / \mathrm{z}$.
Fig. 1 Storage of pine nuts by squirrels in autumn: (A) amounts of pine seeds in the dens of squirrels, (B) mass of pine seeds in the dens of squirrels
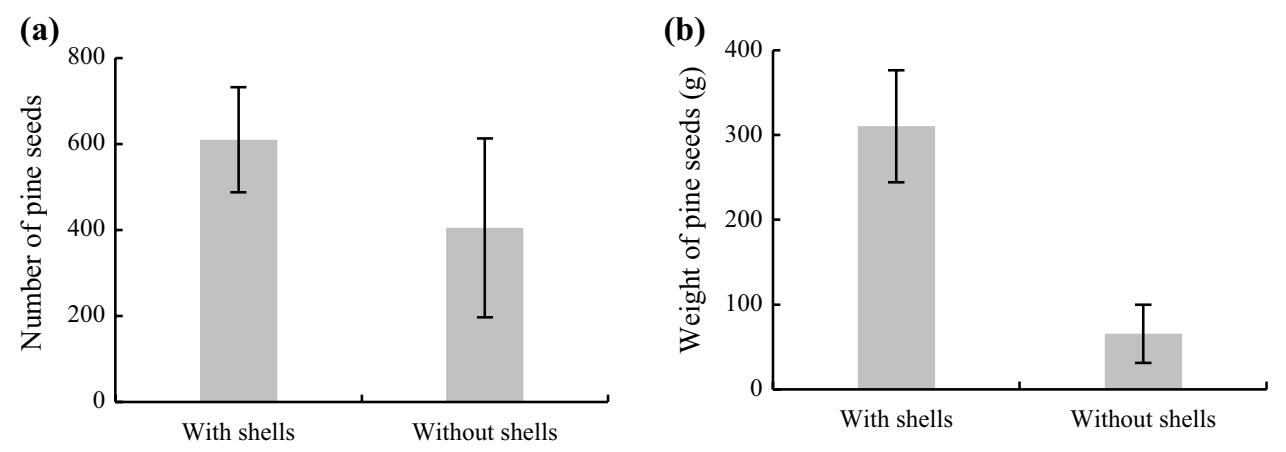


\section{Experimental design in vivo of mice}

\section{Chemicals and materials}

Korean pine nuts were collected from Yichun City, Heilongjiang Province. All enzyme-linked, immunosorbent assay (ELISA) kits were purchased from Jiancheng Bioengineering Institute, Nanjing, Jiangsu Province. Simvastatin (purity $>99 \%$ ) was purchased from Hangzhou Moshadong Pharmaceutical Co., Ltd.. Other chemicals applied in the tests were analytical grades.

\section{Animals and diets}

Kunming male mice $(n=60,22 \pm 2$ g, 4 weeks old) were purchased from the Jinan Punyue Laboratory Animal Breeding Co., Ltd., Jinan, China. The mice were individually isolated in plastic cages and provided food and water at controlled temperatures $\left(23{ }^{\circ} \mathrm{C} \pm 2{ }^{\circ} \mathrm{C}\right)$, humidity $(55 \% \pm 5 \%)$ and light (12 h light-dark cycle). All animal procedures were administered in accordance with the Regulations on the Administration of Laboratory Animals in Heilongjiang Province (P. R. China).

\section{Experimental design}

The mice were fed a normal chow diet for a week and then randomly divided into six groups: the control group were fed a normal chow diet (ND group), the obesity model group (HFD group), the simvastatin intervention SG group ( $4 \mathrm{mg} \mathrm{kg}^{-1}$ ), the L-PNO group ( $4 \mathrm{~mL} \mathrm{~kg}^{-1}$ bw of PNO), the M-PNO group ( $8 \mathrm{~mL} \mathrm{~kg}^{-1}$. bw of PNO) and the H-PNO group (16 $\mathrm{mL} \mathrm{kg}^{-1}$. bw of PNO). Table 1 shows the nutritional composition of the two diets (ND and HFD). Except for the ND group, all the other groups were fed a HFD (highfat diet) for the experimental period. First, the treatment group was fed a HFD in the initial period. After four weeks, the ND and HFD groups were infused with $5 \mathrm{~g} \mathrm{~kg}^{-1}$ physiological saline $(0.9 \% \mathrm{NaCl} w / v)$ per day. The $\mathrm{SG}$ group mice (positive control group) were treated with $4 \mathrm{mg} \mathrm{kg}^{-1}$ simvastatin tablets per day. The PNO groups received intragastric

Table 1 Composition of normal-chow diet and high-fat diet

\begin{tabular}{lllll}
\hline Normal-chow diet & & & High-fat diet & \\
\cline { 1 - 1 } Ingredients & $\%$ & & Ingredients & $\%$ \\
\hline Corn meal & 30 & & Normal-chow diet & 68 \\
Flour & 30 & & Sucrose & 15 \\
Wheat bran & 35 & & Lard & 15 \\
Fish meal & 2 & & Cholesterol & 1.5 \\
Bone meal & 2 & & Cholate & 0.5 \\
Calcium salt & 1 & &
\end{tabular}

administration of the corresponding dose of PNO per day. The experimental design is shown in Fig. 2A. The weight and food intake of each group of mice were recorded weekly. At the end of the treatment, all mice were anaesthetized after 12-h fasting and were then decapitated. Blood samples of all groups were collected and centrifuged to prepare plasma supernatant ( $4000 \mathrm{~g}, 10 \mathrm{~min}$, and $\left.4^{\circ} \mathrm{C}\right)$. Liver, spleen, lungs, kidneys, heart and epididymal adipose tissue were collected, weighed, and stored at $-80{ }^{\circ} \mathrm{C}$. Portions of freshly isolated liver and epididymal tissue were fixed in formalin (10\%) for histopathological evaluation.

\section{Biochemical analysis}

At the indicated times, serum levels of superoxide dismutase (SOD), glutathione peroxidase (GSH-PX), malondialdehyde (MDA), tumor necrosis factor- $\alpha$ (TNF- $\alpha$ ), and interleukin 6 (IL-6) were measured using commercial assay kits. The levels of TC, TG, high-density lipoprotein cholesterol (HDL-C) and LDL-C in serum were also measured using commercial kits. The atherosclerotic index $\left(A_{\mathrm{AI}}\right)$ was obtained by the following (Abbott et al. 1988):

$A_{\mathrm{AI}}=\left(C_{\mathrm{TC}}-C_{\mathrm{HDL}-\mathrm{C}}\right) C_{\mathrm{HDL}-\mathrm{C}}$

where, $C_{\mathrm{TC}}$ is the content of total cholesterol in the serum of mice, and $C_{\mathrm{HDL}-\mathrm{C}}$ is the content of high-density lipoprotein cholesterol in the serum of mice.

\section{Histological analysis}

After fixation, the organs were dehydrated in graduated ethanol and the fixed liver and epididymal fat tissues were cleared in xylene and embedded in paraffin. The tissue blocks were the cut in continuous slices and stained with hematoxylin and eosin (H\&E). The sections were observed under an Olympus light microscope (Tokyo, Japan) at $100 \times$ magnification for routine morphological evaluation.

\section{DNA extraction and high-throughput sequencing}

Before the end of the experiment, the feces of mice in each group (approximately $250 \mathrm{mg}$ ) were collected, frozen in liquid nitrogen, and immediately stored at $-80{ }^{\circ} \mathrm{C}$. The total microbial genomic DNA was extracted according to the the OMEGA E.Z.N.A.TM Mag-Bind Soil DNA Kit (Thermo Fisher China Co. Ltd., Shanghai, China). The V3-V4 regions of bacterial 16S rRNA were amplified by the consensus primers 341F (CCTACGGGNGGCWGCAG) and 805R (GAC TACHVGGGTATCTAATCC). The PCR products of the V3-V4 regions were purified using the AxyPrep DNA Gel Extraction Kit (Axygen Biosciences Inc., Union City, CA, USA) and quantified using the Qubit3.0 DNA Detection Kit 
(a)

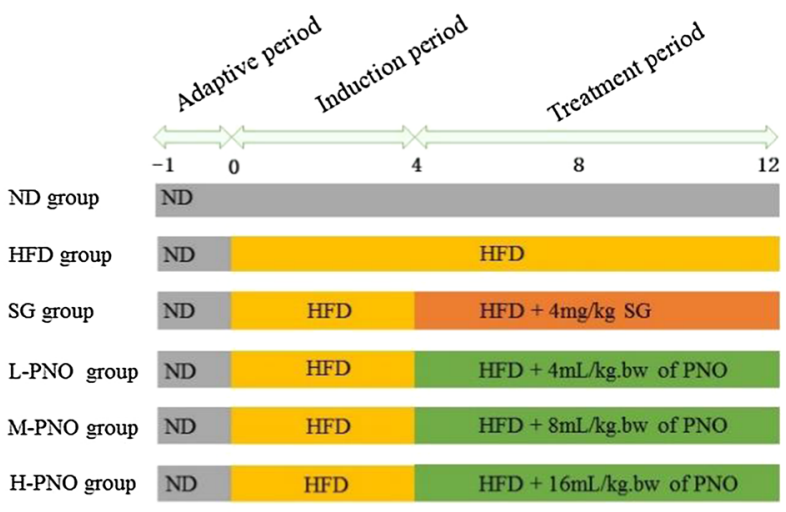

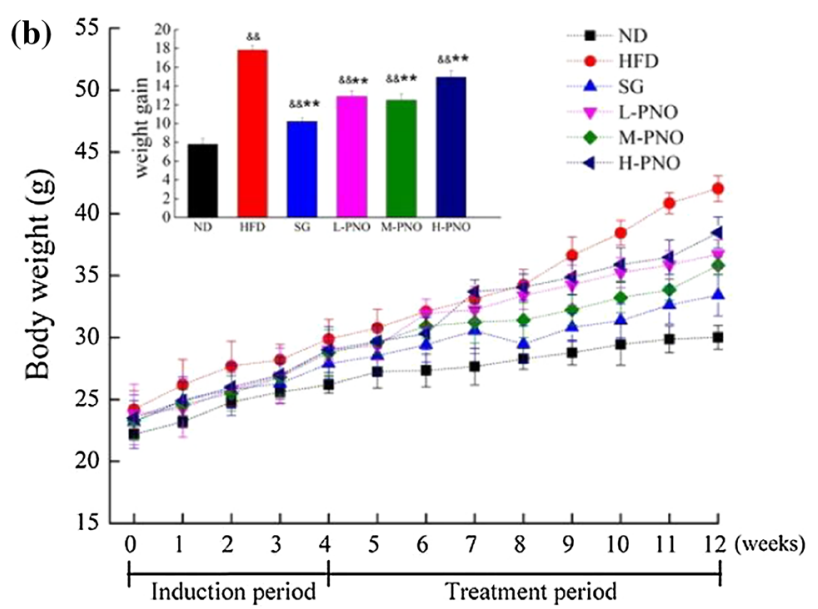

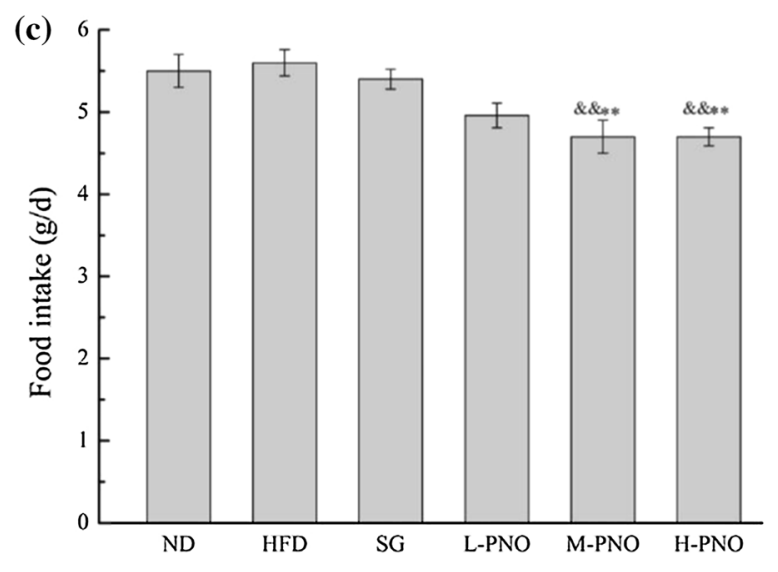

Fig. 2 Scheme of the study design and PNO reduced weight gain in HFD-fed mice: a scheme of the study design in 20 weeks; $\mathbf{b}$ body weight gain; $\mathbf{c}$ food intake

(Thermo Fisher, China). Illumina MiSeq sequencing technology was used for PCR amplification and sequencing analysis of the samples at a read length of $2 \times 300$ bp (Illumina, San Diego, CA, USA). After extracting the high-quality amplified sequences, the nonconforming sequences were removed through quality control filtration, and the samples obtained were analyzed by operational taxonomic unit (OTU) clustering analysis, species classification analysis, and flora difference classification analysis.

\section{Statistical analysis}

All data are presented as the mean $\pm \mathrm{SD}$ (standard deviation). The results were considered statistically significant at $P<0.05$. Analysis of variance (ANOVA) was performed using SPSS 19 (SPSS, Inc., Chicago, IL, USA).

\section{Results}

\section{Food composition of squirrels}

In the field observations, we found that squirrels fed on 12 and nine species of plants in the spring and summer, respectively (Tables 2 and 3). In spring, the feeding frequency on each kind of food was significantly different (chi-square test, $\left.\chi^{2}=106.136, d f=11, P<0.0001\right)$, among which Corydalis ambigua Cham. et Schlecht. was the highest, followed by Lathyrus quinquenerviu (Miq.) Litv. In summer, there were significant differences in the feeding frequency on each type of food (chi-square test, $\chi^{2}=18.40, d f=8, P=0.018$ ), of which Pilea pumila (L.) A. Gray was the highest, followed by Impatiens nolitangere L. In autumn, squirrels fed almost exclusively on Korean pine seeds, significantly 
Table 2 Food composition of squirrels in spring

\begin{tabular}{llll}
\hline Latin name & $\begin{array}{l}\text { Feeding frequency } \\
(\mathrm{d})\end{array}$ & Proportion (\%) & Feeding sites \\
\hline Corydalis ambigua & 38 & 32.20 & Flowers, leaves \\
Pinus koraiensis & 16 & 13.56 & Bark, pine needle, seeds \\
Lathyrus quinquenervius & 12 & 10.17 & Leaves \\
Hylomecon Japonicum & 10 & 8.47 & Leaves, flowers \\
Anemone amurensis & 8 & 6.78 & Leaves, flowers \\
Fraxinus mandschurica & 8 & 6.78 & Seeds \\
Populus ussuriensis & 6 & 5.08 & Inflorescence \\
Acanthopanax senticosus & 6 & 5.08 & Bud \\
Ulmus davidiana var & 6 & 5.08 & Twig, leaves \\
Acer mono Maxim & 4 & 3.39 & Seeds \\
Filipendula palmata & 2 & 1.69 & Leaves \\
Fruticicolidae & 2 & 1.69 & Snail (Animal foods) \\
\hline
\end{tabular}

Table 3 Food composition of squirrels in summer

\begin{tabular}{llll}
\hline Latin name & $\begin{array}{l}\text { Feeding } \\
\text { frequency } \\
\text { (d) }\end{array}$ & Proportion (\%) & Feeding sites \\
\hline $\begin{array}{l}\text { Pilea pumila } \\
\begin{array}{l}\text { Impatiens nolitangere } \\
\text { Linn }\end{array}\end{array}$ & 14 & 15.56 & Leaves \\
Vicia sepium & 12 & 13.33 & Leaves, flowers \\
Caltha palustris L & 10 & 11.11 & Leaves \\
$\begin{array}{l}\text { Phryma leptostachya } \\
\text { L }\end{array}$ & 8 & 8.89 & Leaves \\
$\begin{array}{l}\text { Actinidia kolomikta } \\
\text { Pinus koraiensis }\end{array}$ & 8 & 8.89 & Fruit \\
$\begin{array}{l}\text { Rubia cordifolia } \\
\text { Fruticicolidae, }\end{array}$ & 8 & 8.89 & $\begin{array}{l}\text { Seeds } \\
\text { Pheretima }\end{array}$ \\
& 4 & 6.67 & $\begin{array}{l}\text { Leaves } \\
\text { Snail, earth- } \\
\text { worm (Ani- } \\
\text { mal foods) }\end{array}$ \\
\hline
\end{tabular}

Table 4 Food composition of squirrels in autumn

\begin{tabular}{llcl}
\hline Latin name & $\begin{array}{l}\text { Feeding fre- } \\
\text { quency (d) }\end{array}$ & Proportion (\%) & Feeding sites \\
\hline Pinus koraiensis & 50 & 96.15 & Seeds \\
Fruticicolidae & 2 & 3.85 & $\begin{array}{c}\text { Earthworm } \\
\text { (Animal } \\
\text { foods) }\end{array}$ \\
\hline
\end{tabular}

higher than that of other foods (chi-square test, $\chi^{2}=44.308$, $d f=1, P<0.0001)$. During the observation period, squirrels fed on animal food (earthworm) twice and the rest of the time ate only Korean pine seeds (Table 4). In each season, the food of squirrels included herbaceous and woody plants and animal foods, with significant differences in feeding frequency (Table 5). In spring and summer, squirrels eat a higher proportion of herbaceous plants, while in autumn
Table 5 Variety of food composition in different seasons

\begin{tabular}{lcll}
\hline Seasons & Herb (\%) & Woody plants $(\%)$ & $\begin{array}{l}\text { Animal } \\
\text { food } \\
(\%)\end{array}$ \\
\hline Spring & 64.71 & 33.33 & 1.96 \\
Summer & 77.78 & 17.78 & 4.44 \\
Autumn & 0.00 & 96.15 & 3.85 \\
\hline
\end{tabular}

they eat a higher proportion of woody plants. The proportion of squirrel feeding on animal food did not vary much from season to season, indicating that squirrels are almost completely herbivores.

\section{Food stored by squirrels in autumn}

Pine seeds are almost the only type of food squirrels stored. In the six storage sites, the average number of pine nuts with shells and without shells was $610 \pm 122$ and $405 \pm 208$; there was no significant difference in the number of pine seeds with and without shells (Fig. 1). The results show that squirrels often removed the outer shell during feeding. At each storage site, the average storage was $310.5 \pm 66.2 \mathrm{~g}$ of pine seeds with shells and $65.4 \pm 34.55 \mathrm{~g}$ without shells. The mass of pine seeds with shells was significantly different from that of seeds without shells (ANOVA, $F_{1,10}=10.793$, $P=0.008$, Fig. 1).

\section{Fatty acids composition of PNO}

Unsaturated fatty acids of PNO comprised more than $89 \%$ of pine nut oil, main ones being linoleic acid and oleic acid, accounting for $47.7 \%$ and $25.4 \%$, respectively (Table 6). This result is in agreement with Imbs et al. (1998). Linoleic acid and oleic acid have positive effects on preventing and 
Table 6 Fatty acid compositions of PNO

\begin{tabular}{ll}
\hline Fatty acid & $\begin{array}{l}\text { Relative } \\
\text { content } \\
(\%)\end{array}$ \\
\hline C16:0 & 3.57 \\
C18:0 & 6.37 \\
C18:1 & 25.36 \\
C18:2 (Linoleic acid) & 47.67 \\
C18:3 (Pinolenic acid) & 14.19 \\
C18:3 & 1.36 \\
C20:0 & 0.50 \\
C20:2 & 0.67 \\
C21:0 & 0.13 \\
C22:0 & 0.18 \\
Unsaturated fatty acid (UFA) & 89.25 \\
\hline
\end{tabular}

treating atherosclerosis and cardiovascular disease. Pinolenic acid (PLA) was $14.2 \%$, similar to that reported by Xie et al. (2016). Zhang et al. (2019) showed that PLA improved nonalcoholic fatty liver disease by regulating lipid levels and inhibiting lipid accumulation, oxidative stress, and inflammation. Saturated fatty acids comprised $10.7 \%$ of the total fatty acids and included palmitic, stearic and myristic acids.

\section{Effect of PNO supplements on body organ weight, and fat accumulation}

The effect of PNO supplementation on body and organ weight in mice are presented in Fig. 2 and Table 7. Body weights in each group were recorded weekly. Before the experiment, body weights of all mice were nearly identical. After feeding for 12 consecutive weeks, the weight of mice in the HFD group was significantly higher than that in the ND group (by approximately $75 \%$ ). The weight gain of mice in the PNO groups was remarkably lower than that in the HFD group $(P<0.01$ vs HFD). Food intake of mice in all groups was also tracked. Differences were not statistically significant among the ND, SG, L-PNO and HFD groups, while intake by the M-PNO and H-PNO groups clearly decreased. Compared with the HFD group, PNO supplementation decreased the weight of liver and epididymis adipose tissue compared with ND the group. PNO supplementation increased the weight gain of liver and epididymis adipose tissue. Kidney tissue weight decreased in HFD-fed mice, especially in the HFD group and $\mathrm{SG}$ group $(P<0.05$ vs ND), and in the M-PNO $(P<0.01$ vs ND) group. There were no significant differences in spleen, kidneys, lungs or heart weights $(P>0.5$ vs ND) (Table 7).
Table 7 Effect of PNO on organ weights in hyperlipidemic mice

Table 8 Effect of PNO on lipid levels and the atherosclerosis index in hyperlipidemic mice

\begin{tabular}{|c|c|c|c|c|c|c|}
\hline \multirow[t]{2}{*}{ Organ } & \multicolumn{6}{|c|}{ Tissue index $(\mathrm{g} / \mathrm{g}, \times 100)$} \\
\hline & ND & HFD & SG & L-PNO & M-PNO & H-PNO \\
\hline Epididymal fat & $1.93 \pm 0.72$ & $5.49 \pm 1.33^{\& \&}$ & $4.46 \pm 1.40^{\& \&}$ & $3.50 \pm 0.57^{\& \&}$ & $2.07 \pm 0.70 * *$ & $2.57 \pm 1.56^{*}$ \\
\hline Liver & $3.59 \pm 0.74$ & $4.46 \pm 0.48^{\& \&}$ & $4.41 \pm 0.18$ & $4.21 \pm 0.68$ & $3.83 \pm 0.12 *$ & $3.75 \pm 0.28^{*}$ \\
\hline Spleen & $0.26 \pm 0.10$ & $0.20 \pm 0.05$ & $0.26 \pm 0.09$ & $0.23 \pm 0.11$ & $0.22 \pm 0.11$ & $0.19 \pm 0.02$ \\
\hline Kidney & $1.62 \pm 0.09$ & $1.27 \pm 0.20^{\&}$ & $1.37 \pm 0.16^{\&}$ & $1.32 \pm 0.25$ & $1.19 \pm 0.20^{\& \&}$ & $1.27 \pm 0.27$ \\
\hline Lung & $0.56 \pm 0.04$ & $0.49 \pm 0.07$ & $0.48 \pm 0.04$ & $0.50 \pm 0.12$ & $0.49 \pm 0.07$ & $0.53 \pm 0.06$ \\
\hline Heart & $0.53 \pm 0.06$ & $0.54 \pm 0.08$ & $0.54 \pm 0.07$ & $0.54 \pm 0.09$ & $0.52 \pm 0.15$ & $0.58 \pm 0.02$ \\
\hline
\end{tabular}

Data are expressed as mean $\pm \mathrm{SD}(\mathrm{n}=10) .{ }^{\&}$ represents $P<0.05$ vs ND, * represents $P<0.05$ vs HFD

\begin{tabular}{llllll}
\hline Group & \multicolumn{2}{l}{ Concentration $(\mathrm{mmol} / \mathrm{L})$} & \multirow{2}{*}{$A_{\mathrm{AI}}$} \\
\cline { 2 - 5 } & TC & TG & HDL-C & LDL-C & \\
\hline ND & $2.55 \pm 0.34$ & $1.44 \pm 0.35$ & $7.28 \pm 0.15$ & $1.37 \pm 0.31$ & $0.19 \pm 0.04$ \\
HFD & $4.95 \pm 0.56^{\& \&}$ & $2.88 \pm 0.34^{\&}$ & $3.32 \pm 0.15^{\& \&}$ & $2.98 \pm 0.12^{\& \&}$ & $0.91 \pm 0.09^{\& \&}$ \\
SG & $3.97 \pm 0.56^{\text {\& }}$ & $2.21 \pm 0.34$ & $4.71 \pm 0.04^{\& \& * *}$ & $1.88 \pm 0.68^{*}$ & $0.40 \pm 0.18^{*}$ \\
L-PNO & $4.80 \pm 0.34^{\& \&}$ & $1.52 \pm 0.27^{*}$ & $4.65 \pm 0.11^{\& \& * *}$ & $2.06 \pm 0.19^{* *}$ & $0.44 \pm 0.06^{\& \& * *}$ \\
M-PNO & $3.37 \pm 0.67^{*}$ & $1.17 \pm 0.73^{*}$ & $4.29 \pm 0.11^{\& \& * *}$ & $1.76 \pm 0.05^{* *}$ & $0.41 \pm 0.01^{\& \& * *}$ \\
H-PNO & $3.15 \pm 0.34^{*}$ & $1.28 \pm 0.30^{*}$ & $5.12 \pm 0.06^{\& \& * *}$ & $1.82 \pm 0.18^{* *}$ & $0.36 \pm 0.04^{\& \& * *}$ \\
\hline
\end{tabular}

Data are expressed as mean $\pm \mathrm{SD}(\mathrm{n}=10) .{ }^{\&}$ represents $P<0.05$ vs ND, * represents $P<0.05$ vs HFD 


\section{Effect of PNO supplements on serum lipid levels and the atherosclerosis index}

TC, TG and LDL-C levels increased, while the HDL-C levels decreased notably in the HFD group compared to the ND group $(P<0.01$; Table 8$)$. After supplementation with PNO, serum lipid (TG, TC) levels of mice in the $\mathrm{M}-\mathrm{PNO}$ and H-PNO groups decreased; the differences were statistically significant compared with those in the
HFD group $(P<0.05)$. Furthermore, PNO supplements significantly improved HDL-C levels and decreased LDL-C levels $(\mathrm{P}<0.01)$.

The HFD group had significantly higher atherosclerotic index $\left(A_{\mathrm{AI}}\right)$ values than the ND group. Feeding with a high-fat diet (HFD) could significantly increase the incidence of atherosclerotic disease in mice. The PNO group showed a decrease in the $A_{\mathrm{AI}}$ index of the HFD group by $52 \%, 56 \%$ and $60 \%$, respectively $(P<0.05) . A_{\mathrm{AI}}$ (a)

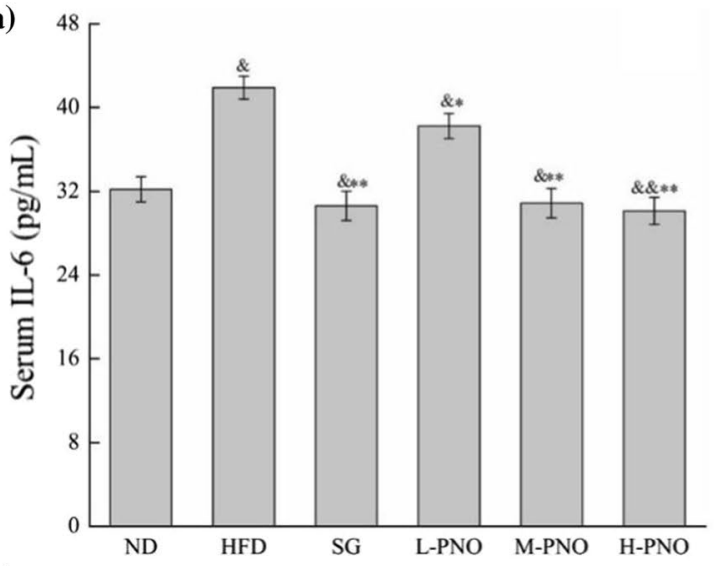

(c)

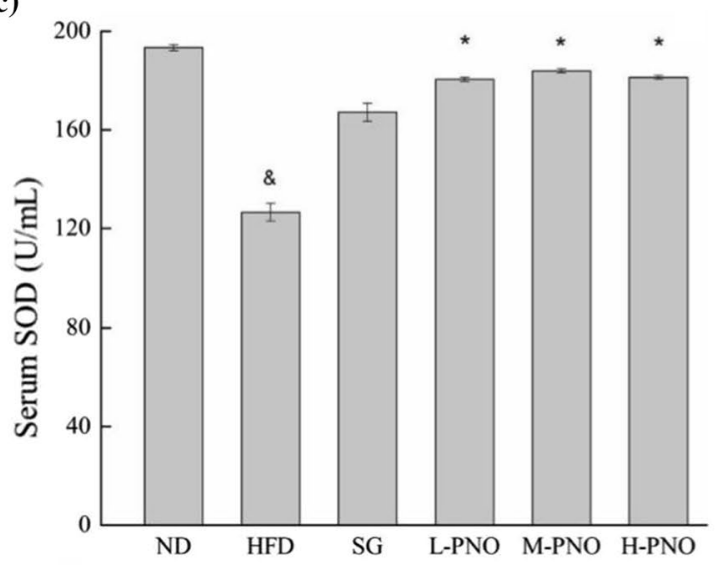

(b)

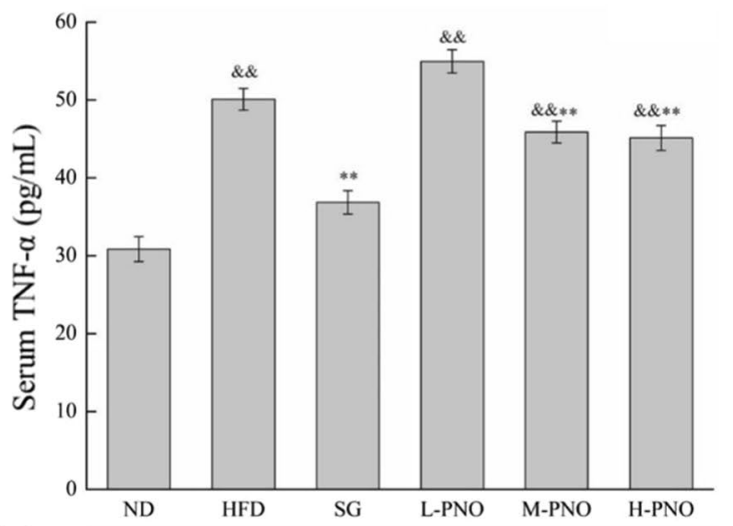

(d)

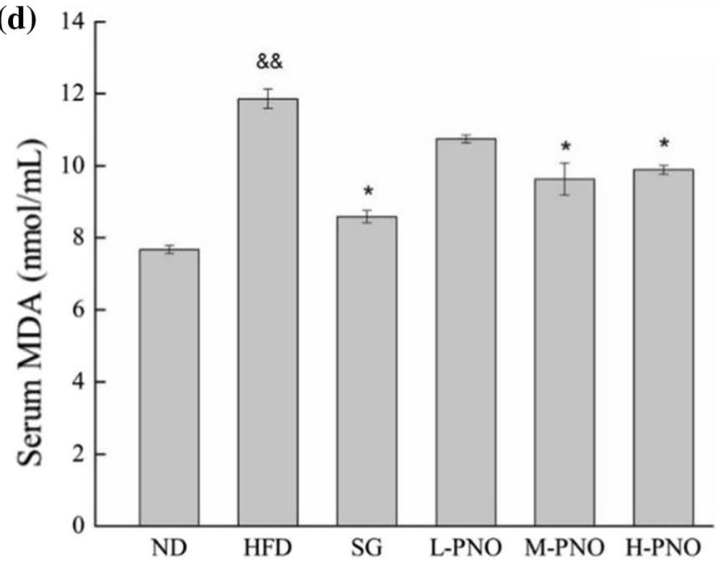

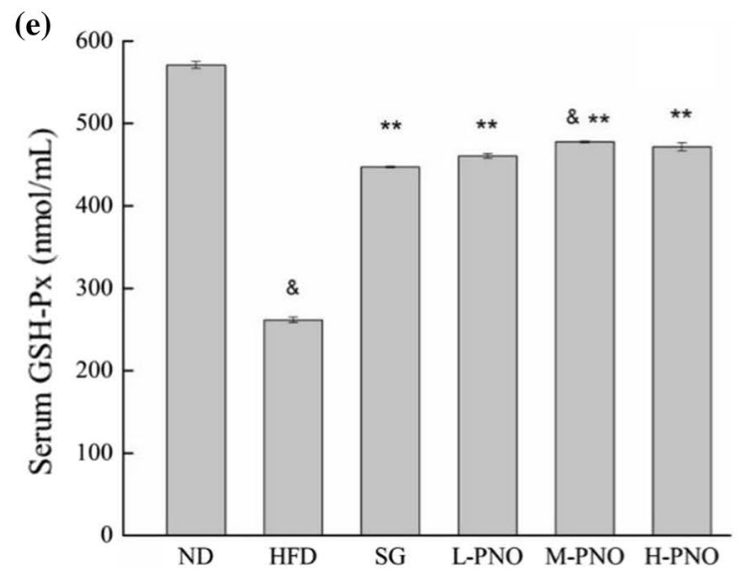

Fig. 3 Effect of PNO supplement on oxidative stress levels in serum 
indicates the degree of atherosclerosis and occurrence of CVD.

\section{Effect of PNO supplements on serum antioxidant enzymes and lipid peroxide}

Activity of the main antioxidant enzymes (GSH-PX and SOD) and malondialdehyde (MDA) content were measured in mouse serum (Fig. 3a-c). SOD and GSH-PX levels of the PNO groups increased significantly compared to those of the HFD group. MDA, a product of lipid peroxidation, decreased $(P<0.05)$. SOD and GSH-PX levels of the HFD group were lower than those in the ND group $(P<0.05)$. Compared with the HFD group, SOD levels of the PNO groups (L-PNO, M-PNO, H-PNO) increased by $42.6 \%, 45.4 \%$ and $43.3 \%$, respectively; GSH-PX levels (L-PNO, M-PNO, H-PNO) increased by $76 \%, 82.6 \%$, and $80.3 \%$, respectively $(P<0.01)$; the MDA content of the PNO groups (L-PNO, M-PNO, H-PNO) decreased by $9.4 \%, 18.8 \%$ and $16.6 \%$, respectively $(P<0.05)$.

\section{Effect of PNO supplements on levels of inflammatory cytokines}

The effects of PNO intake on mouse serum inflammatory factor levels are presented in Fig. 3d-e and were measured to determine whether supplementation with PNO could alleviate the HFD-induced inflammatory response in mice. The findings show that the high-fat diet group had higher levels of TNF- $\alpha$ and IL- 6 than the normal diet group. TNF- $\alpha$ and IL-6 levels were remarkably higher in mice with PNO supplementation than in the HFD group $(P<0.05)$.

\section{Histological analysis of liver and epididymal fat tissue}

The structure of the hepatic lobe in the ND group was clearly observed, and the hepatocytes were all arranged radially around the center of the hepatic lobules (Fig. 4). Mouse liver tissues of the ND group showed no obvious pathological changes in hepatocytes. Compared with normal liver tissues, the HFD group exhibited apparent injury. Lipid droplet accumulation, lipid vacuole increase, hepatocyte ballooning and inflammatory cell infiltration were observed, which is consistent with Han et al. (2015). The effects of PNO on epididymal fat tissue cells in hyperlipidemic mice are shown

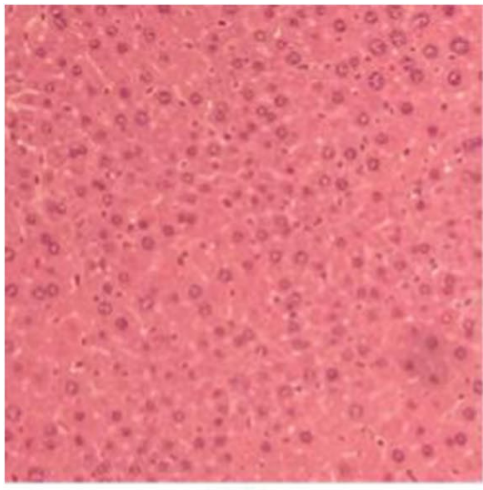

ND

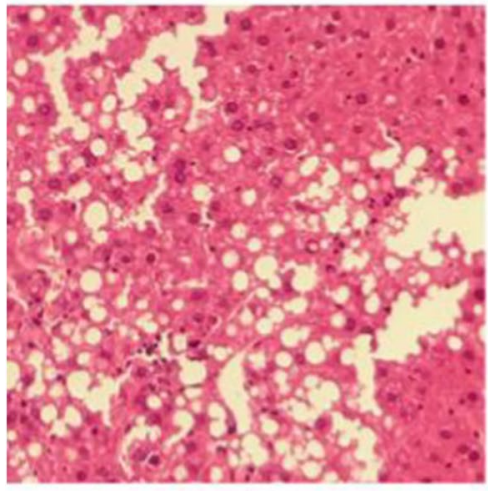

L-PNO

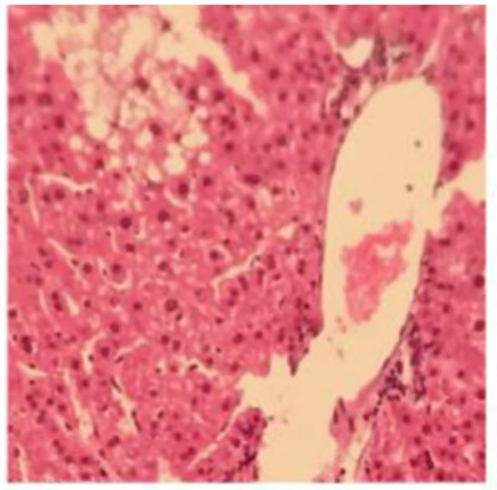

HFD

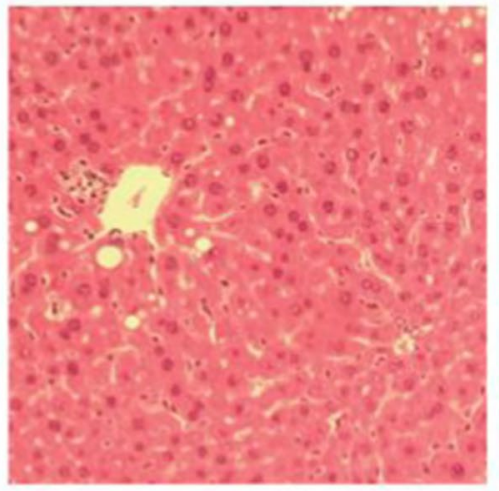

M-PNO

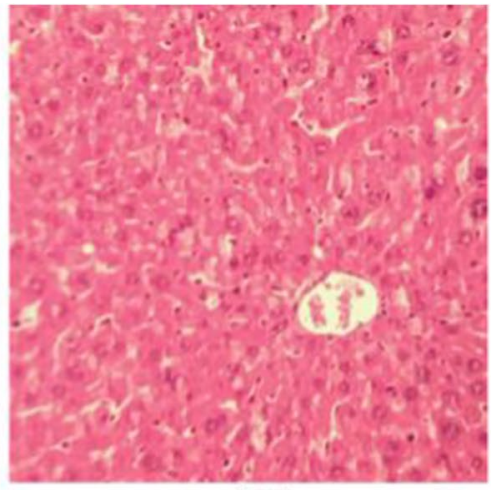

SG

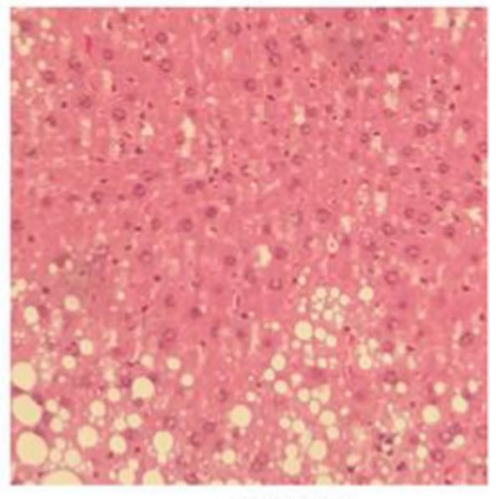

$\mathrm{H}-\mathrm{PNO}$

Fig. 4 H\&E staining of liver section of mice in each group (magnification $100 \times$ ) 


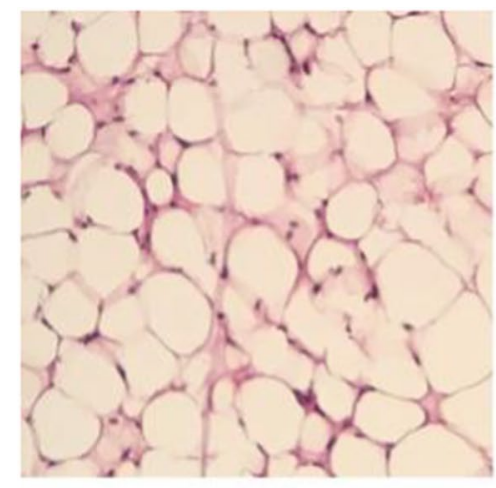

ND

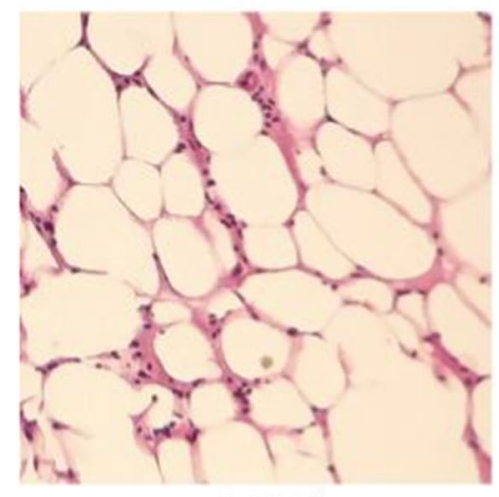

L-PNO

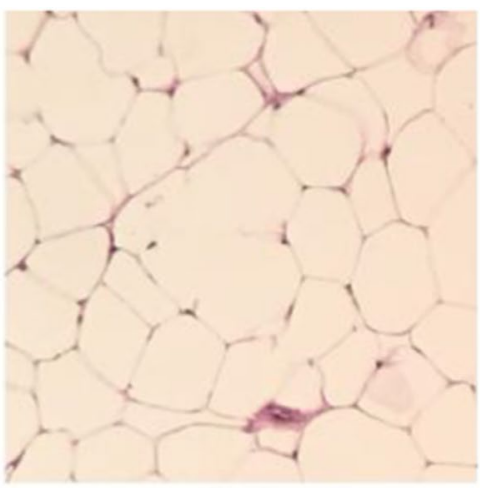

HFD

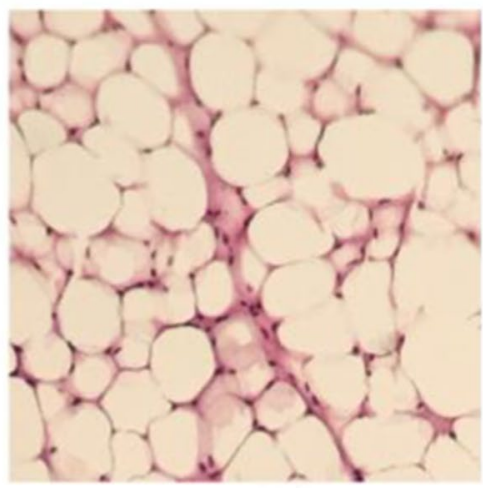

$\mathrm{M}-\mathrm{PNO}$

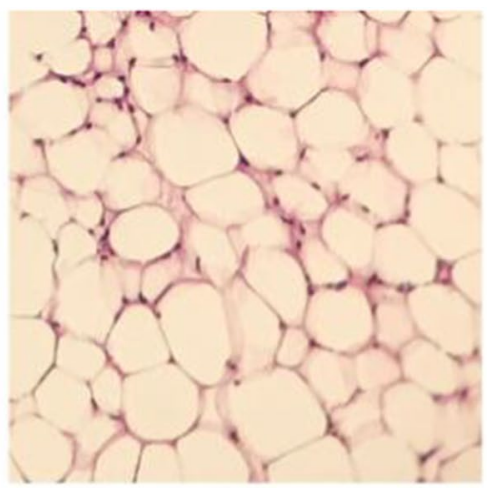

SG

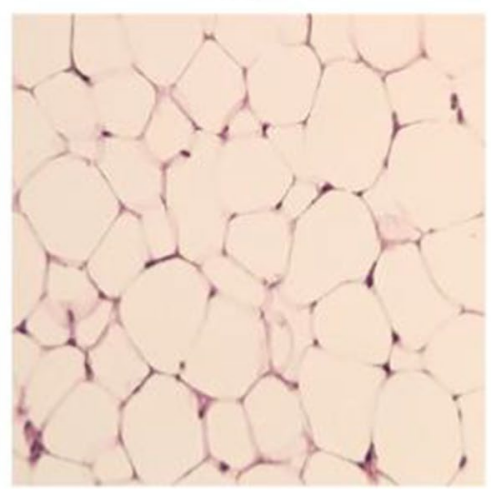

$\mathrm{H}-\mathrm{PNO}$

Fig. 5 H\&E staining of epididymal fat tissue of mice in each group (magnification $100 \times$ )

in Fig. 5. The size of fat cells of the HFD group became larger and deformed with uneven chromatin distribution and visible fat droplets. Nevertheless, the adipose cell diameter in the PNO groups decreased noticeably, and the number of fat cells within the same field of vision increased compared to the HFD group. The results reveal that PNO can reduce fat accumulation in fat cells.

\section{Effects of PNO supplements on diversity and richness indices of gut microbiota}

High-throughput sequencing was applied to assess the effect of PNO supplements on intestinal microbiota in HFD mice. Using the RDP classifier Bayesian algorithm, with a 97\% similarity level, taxonomic analysis was carried out on the sequence of each operational taxonomic unit (OTU) to acquire the species classification information corresponding to each OTU. Fecal samples of each group of mice were collected for 16S rRNA gene sequencing. A total of 269,016 high-quality sequences were obtained from the V3-V4 region of the $16 \mathrm{~S}$ rRNA. After removing the low-quality reads, 233,698 OTUs at a 97\% similarity level were retained. The average sequence number was 67,254, while the average length was $458 \mathrm{bp}$. According to the Venn diagram shown in Fig. 6a, we can determine the number of OTUs shared by the two groups which can analyze the similarities between different samples. As shown in Fig. 6a, compared with 842 OTUs in the ND group, the number in the HFD group decreased to 802 . Notably, among the four groups, the M-PNO group showed the fewest OTUs. PNO supplementation did not increase the number of OTUs.

The relative proportions of the major groups at the phylum and genus levels were analyzed to identify changes in the composition of intestinal microbial microbes. At the phylum level (Fig. 6b), a total of 13 phyla were detected, among which Firmicutes, Bacteroidetes, Verrucomicrobia and Proteobacteria were common to all groups. The levels of Firmicutes and Bacteroidetes were notably different and were dominant in the gut microbiota. The HFD group had a relatively high proportion of Firmicutes (60.5\% vs ND, 56.7\%), and a relatively low proportion of Bacteroidetes (32.7\% vs ND, 35.3\%), and the Firmicutes/Bacteroidetes (F/B) ratio was higher than in the ND group $(P<0.05)$. Compared with the HFD group, the SG group showed an increased relative abundance of Bacteroidetes (39.3\% vs HFD, $32.7 \%$ ), a relatively low proportion of Firmicutes (58.1\% vs HFD, 60.5\%) and a decrease in the F/B ratio $(P<0.05)$. The $\mathrm{F} / \mathrm{B}$ ratio is associated with weight gain in the host. The proportions of Bacteroidetes (21.7\% vs HFD, 32.7\%) and Firmicutes (53.9\% vs HFD, $60.5 \%$ ) decreased in the M-PNO group. 
(a)

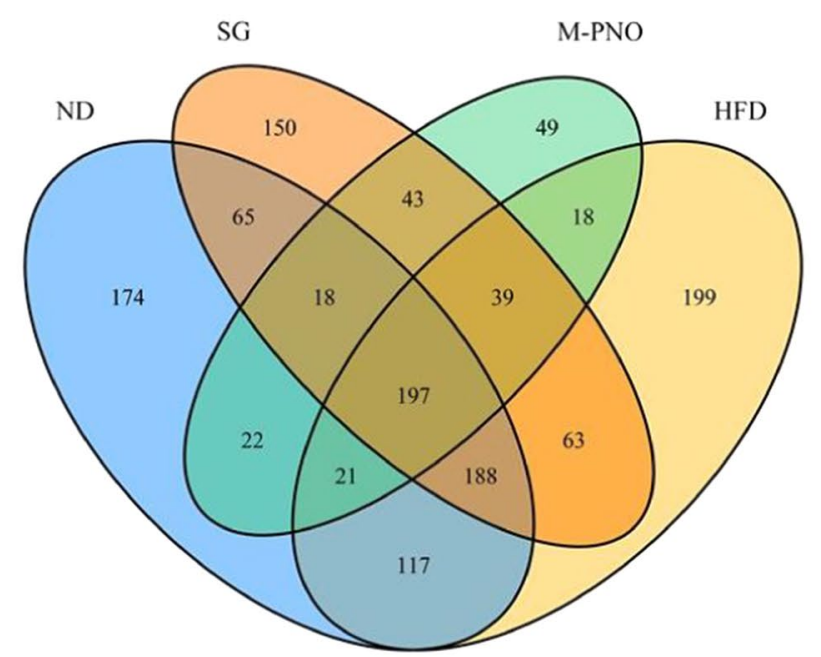

(b)

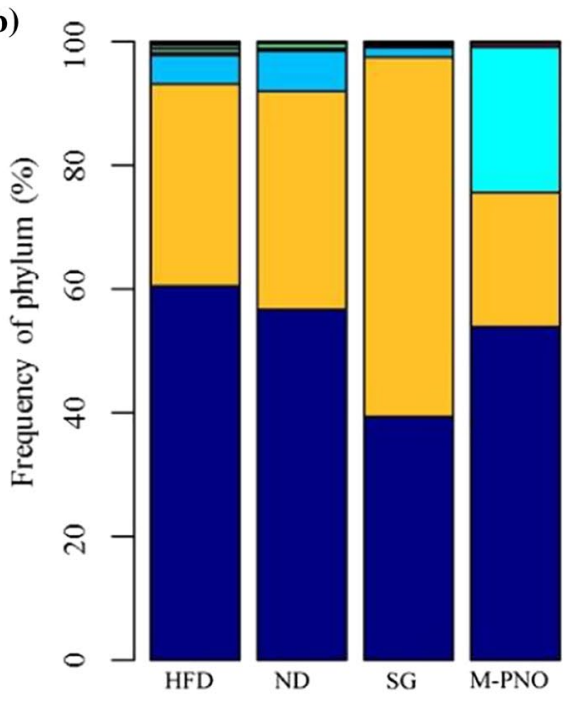

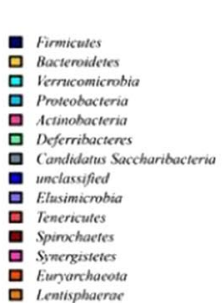

(c)
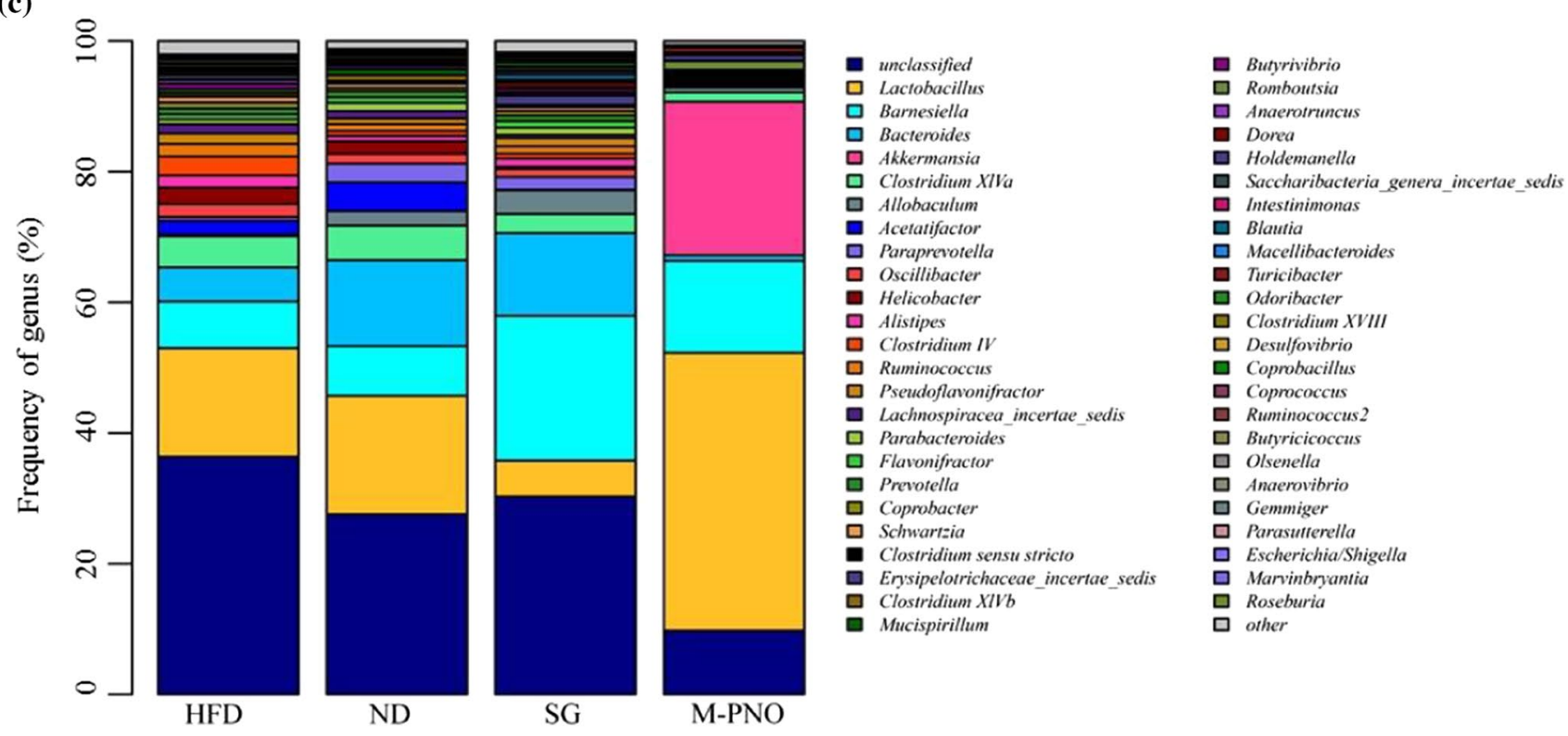

Fig. 6 Composition and abundance of gut microbiota; (A) Venn diagram of overlap in species of mice from each group, (B) relative abundance of gut microbiota at the phylum level, (C) relative abundance of gut microbiota at the genus level

However, the M-PNO group showed significant upregulation of the relative abundance of Verrucomicrobia (23.5\%) and decreased abundance of Proteobacteria (0.2\% vs HFD, $6.5 \%)$.

At the genus level (Fig. 6c), the main genera in the intestinal microorganisms of mice were Lactobacillus, Barnesiella, Bacteroides, Clostridium XlVa and Akkermansia. The genera were represented at different levels in the four groups. The M-PNO group was enriched in Lactobacillus, Akkermansia, Barnesiella, Clostridium XlVa, Romboutsia, Holdemanella, Bacteroides and Allobaculum more than the HFD group, whereas Lactobacillus, Barnesiella, Bacteroides, Clostridium XlVa, Clostridium IV, Helicobacter, Acetatifactor,
Ruminococcus, Alistipes, Pseudoflavonifractor, Coprobacter and Prevotella were greater in the HFD group. The changes in the gut microbiota of the HFD group were reversed by PNO supplementation, increasing the relative abundance of beneficial bacteria. In the structure of the intestinal flora in the M-PNO group, Lactobacillus accounted for nearly half $(42.5 \%)$ of the total flora and possessed a higher relative abundance than the other three groups. Interestingly, PNO supplementation increased the amount of Akkermansia, which was not observed in the other groups. These results have shown that PNO supplementation can significantly increase the amounts of Lactobacillus, Akkermansia and Barnesiella, regulating the diversity of intestinal microbiota. 


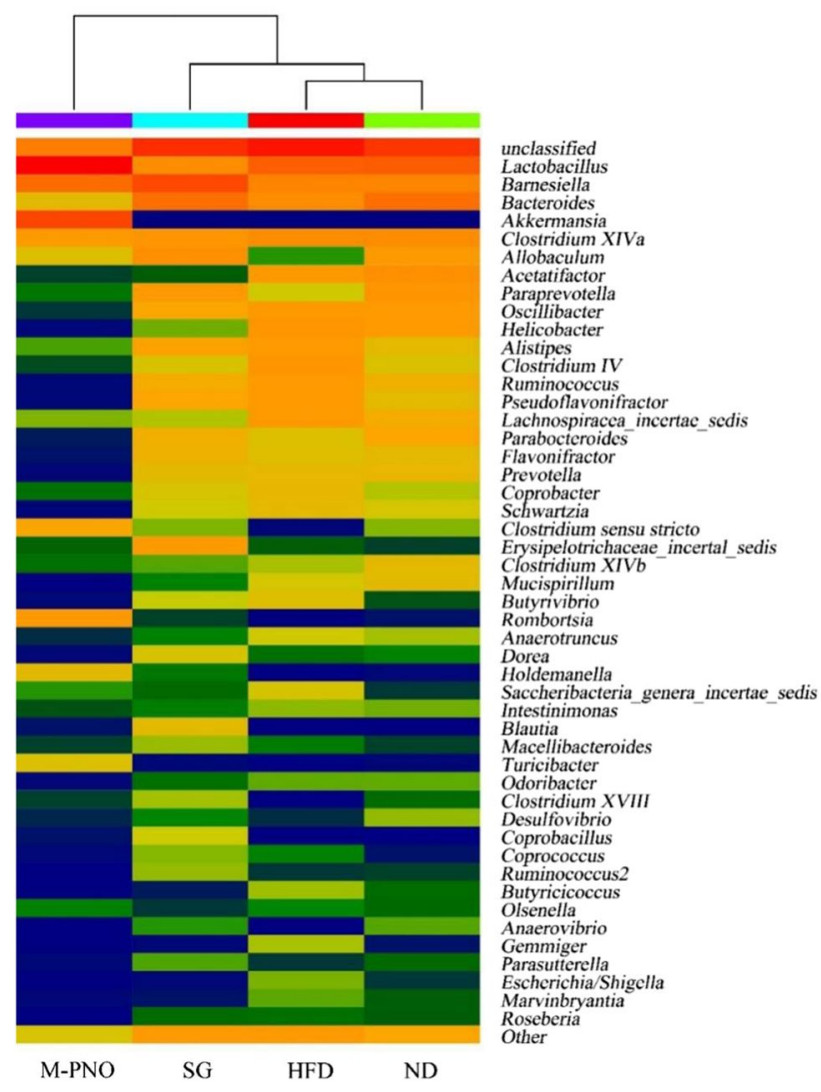

Fig. 7 Heatmap analysis of the gut microbiota at the genus level in different groups; red represents genera with higher abundance in the corresponding samples, and blue the genera with lower abundance

As shown in Fig. 7, the heatmap shows the degree of similarity of the composition of different samples at each classification level. A heatmap analysis of the gut flora at the genus level demonstrated that, although PNO modified the microbial environment of the HFD-induced mice, its environment was not similar to that of the ND group.

\section{Discussion}

The study area is located in the Xiaoxing' an Mountains with distinct seasons and phenological changes in vegetation. Therefore, the availability of food resources in different seasons may be the main reason for the seasonal variation in the food composition of squirrels. The feeding habits of squirrels were observed in different seasons and was mainly plant food and occasionally snails and other small animals. This indicated that squirrels are omnivorous rodents. In spring and summer, herbaceous plants account for a higher proportion of squirrels' food. Because herbaceous plants are abundant and have tender tissues; woody seeds are immature. In autumn, when herbaceous plants gradually decline and woody seeds enter the mature stage, squirrels will choose woody seeds as their main food. The spatiotemporal pattern of food resource distribution in the environment is the basis of selection and food composition of animals. In summer, squirrels tend to feed on herbs that grow in the season, such as Actinidia kolomikta (Maxim. \& Rupr.) Maxim. and Schisandra chinensis (Turcz.) Baill. fresh fruit. The mature period of pine nuts is usually in September and the storage period for squirrels lasts until the end of autumn and the beginning of winter. Squirrels are scatter storage animals, so they can promote the regeneration and diffusion of the Korean pine population (Wauters and Dhondt 1987; Hayashida 1989; Wall 1990; Lee 2002). Through the research on the contents of squirrel storage sites, it was discovered that Korean pine seeds were almost the only kind of food stored in squirrel holes, accounting for more than $95 \%$ of the total food. Occasionally, a few hazelnut and spruce seeds were found.

In autumn, Korean pine seeds mature while other food resources were also abundant and of high quality. However, squirrels almost only feed on Korean pine seeds because they provide adequate energy and are easy to store. In addition, we hypothesize that the effects of the active components of Korean pine seeds on physiological indicators in squirrels may also account for their seed preference. The oil content varies from 31 to $68 \%$ depending on the oil variety (Nergiz and Doenmez 2004), and pine nuts are rich in unsaturated fatty acids, especially linoleic acid. Polyunsaturated fatty acids cannot be synthesized by mammals and must be obtained from an external diet. In previous studies, it was demonstrated that PNO regulates blood lipid levels and lipid metabolism, as well as antioxidant, anti-inflammatory, and antiatherosclerotic activities (Shikov et al. 2008; Chen et al. 2011). Therefore, pharmacological, histological and molecular biological methods were used to compare the effects of a normal diet, a high-fat diet, and a pine nut oil diet on physiological indicators in mice, and the effects on anti-inflammatory, anti-oxidation, lipid levels and intestinal microflora in mice were observed.

In this study, a high-fat diet (HFD) significantly increased body, organ and epididymal fat weights compared with a normal diet (ND). Similarly, research has shown that HFD can cause weight gain in the body, organs and adipose tissue (Wang et al. 2020b). PNO supplementation can also increase the body weight and liver and epididymal fat weights compared with the ND group. Moreover, the food intake of the PNO group was slightly reduced. It is speculated that PNO makes mice feel full. Previous studies revealed that pine nut oil can regulate body weight and appetite by increasing the release of cholecystokinin (CCK) and glucagon-like peptide-1 (GLP-1) (Hughes et al. 2008). In a study by Pasman et al. on overweight postmenopausal women, PNO increased the concentrations of CCK and GLP-1 (Pasman et al. 2008). CCK and GLP-1 are hunger-suppressing hormones released 
by the gastrointestinal tract that can send a fullness signal to the brain and reduce appetites, thus helping to control calorie intake (Alexandra et al. 2006). Therefore, after eating pine nuts, rodents not only obtain energy but also have a sense of satiety, reducing the time of starvation.

However, a high-fat diet can increase the weight and fat of mice. At the same time, it can also lead to excessive accumulation of fat and degeneration of liver cells and adipocytes (Boer et al. 2004). Histological analysis of the liver in this study showed that there were lipid droplets in the liver of HFD-induced hyperlipidemia mice, and the droplets decreased in a dose-dependent manner following PNO treatment. Obesity is characterized by pathological adipocyte aggregation and is accompanied by chronic inflammation. The size of fat cells is an important aspect of the prevention and management of obesity. H\&E staining of epididymal fat showed that adipose cell diameters of the PNO groups of mice decreased noticeably, and the size of fat cells returned to normal levels. Through the comparison of a normal diet, a high-fat diet and a PNO diet, it was found that PNO not only increases the fat accumulation of mice, but also reduces damage caused by a high-fat diet. Excessive lipid accumulation in hepatic tissues leads to lipid metabolism disorders in the body, resulting in hyperlipidemia. It is well-established that the major symptoms of hyperlipidemia are increases in TC (total cholesterol), TG (triglyceride), LDL-C (low-density lipoprotein cholesterol) levels and decreases in HDL-C (high-density lipoprotein cholesterol) levels. In the present study, HFD-induced mice had increased serum cholesterol and TG levels. These results are predictable and consistent with Asset et al. (1999a, b). PNO supplementation can significantly decrease serum TC, TG, and LDL-C levels while elevating HDL-C. HFDs can increase the AI (atherosclerotic index), thereby increasing disease incidence (Fki et al. 2005). Treatment of HFD-fed mice with PNO can reduce the AI, indicating that PNO may contribute to preventing cardiovascular disease.

HFDs can induce the production of free radicals, reduce antioxidant levels and lead to oxidative stress (Jimoh et al. 2018). The occurrence of oxidative stress is related to inflammation (Maritim et al. 2003). Therefore, the regulation of antioxidant enzymes and oxidative stress may be of great significance to alleviate hyperlipidemia. We demonstrated the ability of PNO to regulate enzymes related to oxidative stress and inflammation, leading to inhibition of the development of hyperlipidemia. Previous experiments showed that the diet regulated the activity and expression of antioxidant enzymes. A study by Mukthamba and Srinivasan (2016) demonstrated that garlic oil increased antioxidant enzyme activities in the liver. Another study showed that chia seed oil could prevent hyperlipidemia and oxidative stress by raising the activity of superoxide dismutase (SOD) and glutathione peroxidase (GSH-Px) and reducing the content of malondialdehyde (MDA) (Han et al. 2020). Chen et al. (2016) also reported that PNO increased SOD and GSH-Px activities and reduced the MDA content in the serum compared with the content in a high-lard group, which is consistent with our study. Levels and expression of inflammatory cytokines such as IL-6, TNF- $\alpha$ and IL-1 increased in HFD-induced mice (Spatuzza et al. 2014). Chen et al. (2015) found that pinolenic acid (PLA) decreased the production of nitric oxide (NO), IL-6 and TNF- $\alpha$ in incubating cells. This study shows that PNO supplements can lessen the increase in TNF- $\alpha$ and IL-6 levels in HFD-induced mice. However, the anti-inflammatory mechanism of PNO needs further study.

Changes in diet type and quantity can influence the composition of mammalian gut microflora (Ley et al. 2008a, b). Dietary intervention has an essential impact on the diversity and changes of intestinal flora and have a significant impact on host metabolism (Komaroff 2017). A recent study showed that Firmicutes and Bacteroidetes bacteria play an important role in regulating host lipid metabolism (Pereira et al. 2018). Previous studies suggested that both are crucial for regulating obesity; Bacteroidetes levels decreased and Firmicutes levels increased in obese individuals (Sonnenburg and Bäckhed 2016). Qin et al. (2012) found that HFD-fed mice had more Firmicutes and fewer Bacteroidetes in intestinal microbes than mice on a low-fat diet. In this study, the F/B ratio of the HFD group was higher than that of the ND group, and the effect of $\mathrm{PNO}$ treatment on the F/B ratio was in significant. However, considerable evidence suggests that increases in the Firmicutes/Bacteroidetes (F/B) ratio is not always a reflection of obesity. Researching human gut microbiota found no remarkable difference in $\mathrm{F} / \mathrm{B}$ ratios between obese and control groups (Zhao 2013). Thus, it is necessary to consider the variation of other bacterial phyla or families to evaluate the impact of PNO on intestinal microbiota in hyperlipidemic mice.

Lactobacillus and Akkermansia are beneficial microorganisms that have been found to be negatively correlated with body weight, obesity, and metabolic disorders (Sanchez et al. 2014; Zhou 2017; Wang et al. 2020a). In this study, PNO supplements significantly enhanced levels of both in mice fed a HFD, indicating that PNO is beneficial for the regulation of intestinal flora. Lactobacillus are microorganisms beneficial to host health that ferment sugars to produce lactic acid, and maintain human health and regulate the immune system. Studies have shown that phenolic compounds in olive oil can enrich certain beneficial bacteria, such as Bifidobacterium and Lactobacillus, which are therapeutic for lipid-immune disorders and obesity (Marta Farràs et al. 2020). Akkermansia is a biodegradable mucin bacterium that belongs to the Verrucomicrobia in the human intestine and is inversely related to diabetes, obesity, inflammation and metabolic syndrome (Everard et al. 2013; 
Baldwin et al. 2016). These bacteria may maintain intestinal health by regulating mucus thickness and maintaining the integrity of the intestinal barrier. Akkermansia abundance in obese people is lower than in healthy people. Furthermore, relevant studies have found that the administration of flavonoids, grape polyphenols, carotenes, and dietary fibers and other substances plays a key role in improving the relative proportion of Akkermansia, suggesting that these plant compounds may prevent obesity and metabolic syndrome through prebiotic effects on intestinal flora (Clemente et al. 2012; Sonnenburg and Bäckhed 2016). Taken together, the results show that PNO supplement can increase the abundance of Lactobacillus and Akkermansia to maintain the intestinal health of rodents.

\section{Conclusion}

Pinus koraiensis nut oil (PNO) plays an important role in regulating the health of mice. PNO could significantly reverse the damage of a high-fat diet on mice, increase the abundance of Lactobacillus and Akkermansia, regulate intestinal flora to maintain intestinal health, and improve body immunity. Korean pine seeds have a positive effect on maintaining the health of rodents, which may be the reason why squirrels prefer them. This also confirms our hypothesis that the coevolutionary relationship between squirrels and Korean pine may be related to the effects of seed active ingredients and high nutritional seed value on squirrels. This study would provide a fresh direction for the study of the cooperative evolution of scatter-hoarding rodents and Korean pine.

Open Access This article is licensed under a Creative Commons Attribution 4.0 International License, which permits use, sharing, adaptation, distribution and reproduction in any medium or format, as long as you give appropriate credit to the original author(s) and the source, provide a link to the Creative Commons licence, and indicate if changes were made. The images or other third party material in this article are included in the article's Creative Commons licence, unless indicated otherwise in a credit line to the material. If material is not included in the article's Creative Commons licence and your intended use is not permitted by statutory regulation or exceeds the permitted use, you will need to obtain permission directly from the copyright holder. To view a copy of this licence, visit http://creativecommons.org/licenses/by/4.0/.

\section{References}

Abbott RD, Wilson PWF, Kannel WB, Castelli WP (1988) High density lipoprotein cholesterol, total cholesterol screening, and myocardial infarction. The Framingham Study. Arteriosclerosis 8:207-211

Alexandra WE, Wilrike P, Carina R, Rene vdB, Marianne O'S, Luisa G, Henk H (2006) Korean pine nut fatty acids affect appetite sensations, plasma CCK and GLP-1 in overweight subjects. FASEB J 20(5):A829

Asset G, Bauge E, Wolf RL, Fruchart JC, Dallongeville J (1999a) Pinus pinaster oil affects lipoprotein metabolism in apolipoprotein E-deficient mice. J Nutr 129(11):1972-1978

Asset G, Staels B, Wolff RL, Baugé E, Madj Z, Fruchart JC, Dallongeville J (1999b) Effects of Pinus pinaster and Pinus koraiensis seed oil supplementation on lipoprotein metabolism in the rat. Lipids 34:39-44

Asset G, Bauge E, Wolff RL, Fruchart JC, Dallongeville J (2001) Effects of dietary maritime pine seed oil on lipoprotein metabolism and atherosclerosis development in mice expressing human apolipoprotein B. Eur J Nutr 40:268-274

Baldwin J, Collins B, Wolf PG, Kristina M, Michael KM (2016) Table grape consumption reduces adiposity and markers of hepatic lipogenesis and alters gut microbiota in butter fat-fed mice. J Nutr Biochem 27:761-769

Boer MD, Voshol PJ, Kuipers F, Havekes LM, Romijn JA (2004) Hepatic steatosis: a mediator of the metabolic syndrome. Lessons from animal models. Arterioscler Thromb Vasc Biol 24:644-649

Chen XQ, Zhang Y, Wang ZY, Zu YG (2011) In vivo antioxidant activity of Pinus koraiensis nut oil obtained by optimised supercritical carbon dioxide extraction. Nat Prod Res 25:1807-1816

Chen SJ, Chuang LT, Liao JS, Huang WC, Lin HH (2015) Phospholipid incorporation of non-methylene-interrupted fatty acids (NMIFA) in murine microglial BV-2 cells reduces pro-inflammatory mediator production. Inflammation 38:2133-2145

Chen F, Zhang Q, Gu H, Yang L (2016) An approach for extraction of kernel oil from Pinus pumila using homogenate-circulating ultrasound in combination with an aqueous enzymatic process and evaluation of its antioxidant activity. J Chromatogr A 1471:68-79

Chung MY, Woo H, Kim J, Kong D, Choi IW, Kim IH, Sang KN, Kim BH (2017) Pinolenic acid in structured triacylglycerols exhibits superior intestinal lymphatic absorption as compared to pinolenic acid in natural pine nut oil. J Agric Food Chem 65:1543-1549

Clemente JC, Ursell LK, Parfrey LW, Knight R (2012) The impact of the gut microbiota on human health: an integrative view. Cell 148:1258-1270

Destaillats F, Cruz-Hernandez C, Giuffrida F, Dionisi F (2010) Identification of the botanical origin of pine nuts found in food products by gas-liquid chromatography analysis of fatty acid profile. $\mathrm{J}$ Agric Food Chem 58:2082-2087

Everard A, Belzer C, Geurts L, Ouwerkerk JP, Druart C, Bindels LB, Delzenne NM (2013) Cross-talk between Akkermansia muciniphila and intestinal epithelium controls diet-induced obesity. Proc Natl Acad Sci USA 110:9066-9071

Fki I, Bouaziz M, Sahnoun Z, Sayadi S (2005) Hypocholesterolemic effects of phenolic-rich extracts of Chemlali olive cultivar in rats fed a cholesterol-rich diet. Bioorg Med Chem 13:5362-5370

Gómez JM, Schupp EW, Jordano P (2018) Synzoochory: the ecological and evolutionary relevance of a dual interaction: Synzoochory. Biol Rev 94:12-13

Han JM, Lee JS, Kim HG, Seol IC, Im HJ, Cho JH, Son CG (2015) Synergistic effects of Artemisia iwayomogi and Curcuma longa radix on high-fat diet-induced hyperlipidemia in a mouse model. J Ethnopharmacol 173:217-224

Han K, Li XY, Zhang YQ, He YL, Hu R, Lu XY, Li QJ, Hui J (2020) Chia seed oil prevents high fat diet induced hyperlipidemia and oxidative stress in mice. Eur J Lipid Sci Technol 122(4):1900443

Hayashida M (1989) Seed dispersal by red squirrels and subsequent establishment of Korean pine. For Ecol Manage 28(2):115-129

Hollander JL, Wall S (2004) Effectiveness of six species of rodents as dispersers of singleleaf pion pine (Pinus monophylla). Oecologia 138(1):57-65 
Hou L, Cuicui LI, Qiu J (2018) Comparison of the physicochemical characteristics of Pinus koraiensis 1. nut oils from different extraction technologies. Grain Oil Sci Technol 1(03):5-10

Hughes GM, Boyland EJ, Williams NJ, Mennen L, Scott C, Kirkham TC, Joanne A, Hiskias GK, Jason CGH (2008) The effect of Korean pine nut oil (pinnothinTM) on food intake, feeding behaviour and appetite: a double-blind placebo-controlled trial. Lipids Health Dis 7:1-10

Imbs AB, Nevshupova NV, Pham LQ (1998) Triacylglycerol composition of Pinus koraiensis seed oil. J Am Oil Chem Soc 75:865-870

Jimoh A, Tanko Y, Ahmed A, Mohammed A, Ayo JO (2018) Resveratrol prevents high-fat diet-induced obesity and oxidative stress in rabbits. Pathophysiology 25:359-364

Kaviriri DK, Zhang Q, Zhang X, Jiang L, Zhang J, Wang J, Khasa DP, You X, Zhao X (2020) Phenotypic variability and genetic diversity in a Pinus koraiensis clonal trial in northeastern china. Genes 11(6):673

Komaroff AL (2017) The Microbiome and Risk for Obesity and Diabetes. JAMA 317:355

Le NH, Shin S, Tu TH, Kim CS, Kang JH, Tsuyoshi G, Teruo K, Han SN, Yu R (2012) Diet enriched with Korean pine nut oil improves mitochondrial oxidative metabolism in skeletal muscle and brown adipose tissue in diet-induced obesity. J Agric Food Chem 60:11935

Lee TH (2002) Feeding and hoarding behaviour of the Eurasian red squirrel Sciurus vulgaris during autumn in Holdcaido. Japan Acta Theriologica 47(4):459-470

Ley RE, Hamady M, Lozupone C, Turnbaugh PJ, Ramey RR, Bircher JS, Schlegel ML, Tucker TA, Schrenzel MD, Knight R (2008a) Evolution of mammals and their gut microbes. Science 320(5883):1647-1651

Ley RE, Lozupone CA, Hamady M, Knight R, Gordon JI (2008b) Worlds within worlds: evolution of the vertebrate gut microbiota. Nat Rev Microbiol 6(10):776-788

Lichti NI, Steele MA, Swihart RK (2017) Seed fate and decision-making processes. Biol Rev 92:474-504

Maritim AC, Sanders RA, Watkins JB (2003) Diabetes, oxidative stress, and antioxidants: a review. J Biochem Mol Toxicol 17:24-38

Marta Farràs L, Martinez-Gili PK, Arranz S, Blanco-Vaca F (2020) Modulation of the gut microbiota by olive oil phenolic compounds: implications for lipid metabolism, immune system, and obesity. Nutrients 12:2200

Molinari A, Wauters LA, Airoldi G, Cerinotti F, Martinoli A, Tosi G (2006) Cone selection by Eurasian red squirrels in mixed conifer forests in the italian alps. Acta Oecol 30(1):1-10

Mukthamba P, Srinivasan K (2016) Hypolipidemic and antioxidant effects of dietary fenugreek (Trigonella foenum-graecum) seeds and garlic (Allium sativum) in high-fat fed rats. Food Bioprod Process 14:1-9

Nergiz C, Doenmez I (2004) Chemical composition and nutritive value of Pinus pinea L. seeds. Food Chem 86:365-368

No DS, Zhao TT, Kim Y, Yoon MR, Lee JS, Kim HY (2015) Preparation of highly purified pinolenic acid from pine nut oil using a combination of enzymatic esterification and urea complexation. Food Chem 170:386-393

Pasman WJ, Heimerikx J, Rubingh CM, van den Berg R, O'Shea M, Gambelli L, Hendriks HF, Einerhand AW, Scott C, Keizer HG, Mennen LI (2008) The effect of Korean pine nut oil on in vitro CCK release, on appetite sensations and on gut hormones in postmenopausal overweight women. Lipids Health Dis 7:10

Pereira LTG, Beserra BTS, Engel D, de Paula GC, de Bema AF, Amato AA (2018) Effect of gut microbiota modulation on hepatic lipid metabolism. FASEB J 32(S1):760.13

Qin J, Li Y, Cai Z, Li S, Zhu J, Zhang F, Liang S, Zhang W, Guan Y, Shen D, Peng Y, Zhang D, Jie Z, Wu W, Qin Y, Xue W, Li J, Han
L, Lu D, Wu P, Dai Y, Sun X, Li Z, Tang A, Zhong S, Li X, Chen W, Xu R, Wang M, Feng Q, Gong M, Yu J, Zhang Y, Zhang M, Hansen T, Sanchez G, Raes J, Falony G, Okuda S, Almeida M, Le Chatelier E, Renault P, Pons N, Batto JM, Zhang Z, Chen H, Yang R, Zheng W, Li S, Yang H, Wang J, Ehrlich SD, Nielsen R, Pedersen O, Kristiansen K, Wang J (2012) A metagenome-wide association study of gut microbiota in type 2 diabetes. Nature 490:55-60

Roth JK, Wall S (2005) Primary and secondary seed dispersal of bush chinquapin (Fagaceae) by scatter-hoarding rodents. Ecology 86(9):2428-2439

Sanchez M, Darimont C, DrapeauV ES, Lepage M, Rezzonico E, Tremblay A (2014) Effect of lactobacillus rhamnosus cgmcc1.3724 supplementation on weight loss and maintenance in obese men and women. Br J Nutr 111:1507-1519

Shikov AN, Pozharitskaya ON, Makarov VG, Marina N (2008) Antiinflam matory effect of Pinus sibirica oil extract in animal models. J Nat Med 62:436-440

Silva L, Silva J, Souza CS, Guimares MM, Castro C (2021) Plantanimal interactions of understory species in an area of tropical rainforest, north-eastern Brazil. Austral Ecol 46(4):561-573

Sonnenburg JL, Bäckhed F (2016) Diet-microbiota interactions as moderators of human metabolism. Nature 535:56-64

Soyoung P, Sunhye S, Yeseo L, Jae S, Je S, Sung H (2016) Korean pine nut oil attenuated hepatic triacylglycerol accumulation in high-fat diet-induced obese mice. Nutrients 8(1):59

Spatuzza C, Postiglione L, Covelli B, Ricciardone M, Benvenuti C, Mondola P, Belfiore A (2014) Effects of berberine and red yeast on proinflammatory cytokines IL- 6 and TNF- $\alpha$ in peripheral blood mononuclear cells (pbmcs) of human subjects. Front Pharmacol 5:230

Steele M, Wauters LA, Larsen KW (2005) Selection, predation and dispersal of seeds by tree squirrels in temperate and boreal forests: are tree squirrels keystone granivores? Seed Fate Predat Dispers Seedl Establ Chap 12:205-221

Sundaram Lichti NI, Widmar NJO, Swihart RK (2018) Eastern gray squirrels are consistent shoppers of seed traits: insights from discrete choice experiments. Integr zool 13(3):280-296

Vander W, Dimitri LA, Longland WS, White J (2019) Seed value influences cache pilfering rates by desert rodents. Integr Zool 14:75-86

Wall SBV (1990) Food hoarding in animals. University of Chicago Press, Chicago, pp 1-43

Wall S (2001) The evolutionary ecology of nut dispersal. Bot Rev 67(1):74-117

Wall SV, Jenkins SH (2011) Plant—animal interactions and climate: why do yellow pine chipmunks (Tamias amoenus) and eastern chipmunks (Tamias striatus) have such different effects on plants? Ecoscience 18(2):130-137

Wall S, Joyner JW (1998) Re-caching of jeffrey pine (Pinus jeffreyi) seeds by yellow pine chipmunks (Tamias amoenus): potential effects on plant reproductive success. Can J Zool 76(1):154-162

Wang M, Zhang B, Hu J, Nie S, Xie M (2020a) Intervention of five strains of lactobacillus on obesity in mice induced by high-fat diet. J Funct Foods 72:104078

Wang P, Gao X, Li Y, Wang S, Wei Y (2020b) Bacillus natto regulates gut microbiota and adipose tissue accumulation in a high-fat diet mouse model of obesity. J Funct Foods 68:103923

Wauters LA, Dhondt AA (1987) Activity budget and foraging behavior of the red squirrel. (Sciurus vulgaris L 1758) in a coniferous habitat. Zeitschrift Für Säugetierkunde 52:341-353

Xie KY, Calder PC, Miles EA (2016) A review of the potential health benefits of pine nut oil and its characteristic fatty acid pinolenic acid. J Funct Foods 23:464-473

Zhang YF, Chong W, Tian SL, Lu JQ (2014) Dispersal and hoarding of sympatric forest seeds by rodents in a temperate forest from northern china. Iforest 7(2):70-74 
Zhang J, Zhang SD, Wang P, Guo N, Fu YJ (2019) Pinolenic acid ameliorates oleic acid-induced lipogenesis and oxidative stress via ampk/sirt1 signaling pathway in hepg2 cells. Eur J Pharmacol $861: 172618$

Zhao L (2013) The gut microbiota and obesity: From correlation to causality. Nat Rev Microbiol 11:639-647

Zhou K (2017) Strategies to promote abundance of Akkermansia muciniphila, an emerging probiotics in the gut, evidence from dietary intervention studies. J Funct Foods 33:194-201
Publisher's Note Springer Nature remains neutral with regard to jurisdictional claims in published maps and institutional affiliations. 